\title{
Towards a New Educational Engineering Model for Moroccan University Based on ICT
}

\author{
https://doi.org/10.3991/ijep.v10i3.12421 \\ Meriyem Chergui $(\bowtie)$ \\ National Higher School of Electricity and Mechanics, Casablanca, Morocco \\ chergui.meriyemegmail.com \\ Aziza Chakir \\ Faculty of economic and social legal sciences, Casablanca, Morocco \\ Ahlam Tahiri, Hajar Mansouri \\ National Higher School of Electricity and Mechanics, Casablanca, Morocco
}

\begin{abstract}
Today, Moroccan decision makers of higher education are aware of the importance of digitalization for the improvement of the educational system and their alignment with international standards. The reason why several priority programs have been launched in recent years: Digital Work Environment, Network Virtual Campus and digital gadgets distribution operations. Meanwhile, the pedagogical impact remains limited on the scale of the Substitution, Augmentation, Modification and Redefinition (SAMR) model of Information and Communication Technologies (ICT). The present work relates to an engineering model that aims to reach the level of maturity of successful pedagogical models and to make possible the use of digital tools not only in a quantitative way, but also on qualitative and measurable way compared to the performance indicators of Moroccan university. The aim of the article is to propose a pedagogical meta-model for Moroccan university designed from a national high education perception study. The model is implemented by IMS LD, involving digital tools and different pedagogical objects in an environment which is both educational and entrepreneurial to catch the gaps in methodologies and content. This model allows the teacher to make available to the student necessary information, methods and techniques in an easy way. The model is integrated into a digital environment, dynamic and open to the business world.
\end{abstract}

Keywords - Information Technology, Moroccan university, IMS LD, pedagogic scenario, educational engineering.

\section{Introduction}

Confronted with the revolution of information technologies and working conditions, the diversification of professional trajectories, the demands of continuous training, the disruption of knowledge and the way of learning, the changing relationships between State, business and society, higher education in Morocco must urgently re- 
view its objectives and simplify its organization. These reforms determine the rise of the qualification level of Moroccans, on which depends the standard of living. In fact, with the increase in the number of university students, and the limited available resources, there is a significant defacing of both working market and world's leading universities.

However, the improvement of Higher education requires not only the involvement of ministries in charge of education (with enough resources), but also of teachers, students and socio-economical actors to improve the quality of education and to afford a world-leading program of undergraduate university students, by choosing the right educational method, in the right moment.

An educational method is the way a teacher uses to promote learning and to achieve educational objective. As a general rule, a teacher values more at one time than one method; of course, the single method imposed or mandatory would be an error, because it belongs to the free choice of the teacher and his students and is often a matter of circumstances. Historically, there have been fashion effects or belief at times in a miracle method that would allow everyone to learn. But new methods always eclipse old ones. This attitude in any case influences the choice of Information and Communication Technologies or resources of a project. In this sense, [1] describes four models of ICT integration, from which we have retained the following:

1. The continuum of ICT approaches synthesized by UNESCO in 2004 [2].

2. The SAMR model [3] (Substitution, Increase, Modification and Redefini-tion).

In this work, we propose a new educational engineering model for Moroccan university based on ICT approaches. This model, based on theater metaphor, combines several teaching methods and objects according to the pedagogical scenario in question and not according to the fashion effect. Indeed, new or old teaching methods remain effective in very specific situations and for a given population. Just choose the right method and the right object at the right time. This is the core of our meta-model which used one method and one or more objects per scene. It calls on stakeholders to combine their contributions for a better goal.

This model has been tested on a population of engineering student and has given remarkable results.

This article is organized as following: we will start with definition and state of art of ICTE, after that we will talk about Educational engineering and its different learning models. We will present IMS Learning design as the pedagogical modeling language that we will use in our meta-model. We will detail later Moroccan university specificities via a perception study and its analysis. We will present in the fifth part the proposed meta-model based on IMS DL specification. We will discuss the proposed model through real educational scenarios before a conclusion and perspectives. 


\section{State of Art}

\subsection{Information and communication technologies for learning}

The educational uses of Information and Communication Technologies (ICTE) can be potentially very numerous, but we believe that there is no normative framework allowing the valorization of this or that type of use depending on the context. For [4] it is by taking into account the learners, their characteristics, the objectives pursued, the available resources and the way to use them, that a teacher can reach with the learners the desired pedagogical target with a minimal mastery of digital tools.

Let's talk about ICTE state of art to understand the engineering aspect. The main question is what are the conditions and constraints for integrating ICT in teaching practice? Because ICT are integrated in all fields (transports, health, and food) but what about Teaching and learning?

More than fifteen theoretical models related to the use and integration of ICTE exists. According to [5], some models focus particularly on the ICT integration process, such as the [6] and [7] Concerns-Based Adoption Model (CBAM), while others focuses on the levels of ICT acquisition by teachers, such as [8]. There are also models that combine these last two possibilities. This is the case, for example, with Raby's model [9]. Fiévez proposes a typology including well-known models such as SAMR [10], centered on the role of the tool within the educational relationship, and other models, such as Power, Environment, Teacher, Technology and Learners (PETTaL) [27], which includes, in addition, internal and external factors. Also, there is Technological Pedagogical Content Knowledge (TPACK)[11], which has three dimensions related to teaching. It focuses on both technological and pedagogical knowledge, but also on disciplinary skills.

Let's compare these different learning models according to the three criteria below:

Table 1. ICT education models comparison

\begin{tabular}{|c|c|c|c|}
\hline Models & Content focus & Pedagogical focus & Technological focus \\
\hline$[6]$ & & & $\mathrm{x}$ \\
\hline$[7]$ & & & $\mathrm{x}$ \\
\hline$[8]$ & $\mathrm{x}$ & & $\mathrm{x}$ \\
\hline$[9]$ & $\mathrm{x}$ & & $\mathrm{x}$ \\
\hline$[10]$ & & $\mathrm{x}$ & $\mathrm{x}$ \\
\hline$[11]$ & $\mathrm{x}$ & $\mathrm{x}$ & $\mathrm{x}$ \\
\hline$[27]$ & & $\mathrm{x}$ & \\
\hline
\end{tabular}

From this comparison, we choose TPACK model since it focuses on teacher's technological abilities and knowledge so as to use ICTE positively and effectively without ignoring disciplines specificities. The figure bellow explains TPACK different layers: 


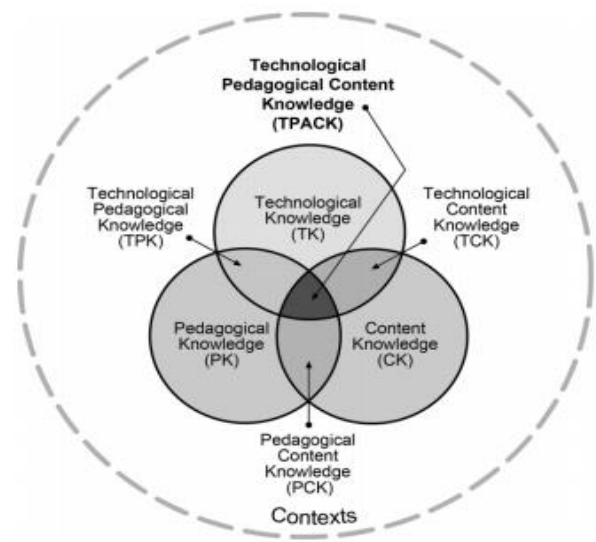

Fig. 1. TPACK Model [11].

The three dimensions of the model mastered individually, without interactions, lead to less effective integration of technologies and consequently, the pedagogical uses of ICT could be weak. Intersections, including the three dimensions (TK, PK and $\mathrm{CK}$ ), are favored so that teachers can integrate both technologies and other facets of teaching. If one of these dimensions is weaker than another, ICT integration may be affected.

We choose this model since it covers three important axes that affect leaning systems and allows a qualitative diagnosis of training or course.

\subsection{Pedagogical engineering}

The term "Educational engineering" began to be used more and more in the 2000s in scientific writings [12]. When the designed learning system becomes a digital educational environment, the term "engineering" is also used. For example, [13] speaks about "engineering of CEHL" (computing environments for human learning). The term courseware engineering is also commonly used [14].

Before, we used the term "Learning Design" which means « a system of procedures for developing consistently education and training programs » [16]. For some authors, replacing the term "design" with "engineering" would only be one way of highlighting the rigorous and systemic nature of an approach that borrows, from various engineering fields.

This approach inherits especially from software engineering for the quest of coherence, efficiency and effectiveness that marks this discipline. For example, [17] note that engineering refers to the design or production of structures, machines or products using scientific methods to make the properties of matter and humans energy. For them, this is exactly what we do when we create effective learning systems we gather the resources and then design, invent, and contrive using every means at a disposal to establish a learning system. 


\subsection{IMS learning design}

The IMS-Learning Design is a learning objects modeling method. A leaning object is a reusable entity with digital view, educational purpose, and attributes: content, learning activities and elements of context.

A learning object has mainly an external structure of information for identification, storage and retrieval called learning object metadata [18].

In 2003, IMS-LD was published by the Instructional Management Systems Global Learning. The source of the proposed language was evaluated by the European Committee for Standardization (CEN) during a comparative study of different Educational Modeling Languages (EML) in 2002.

An EML through the CEN / ISS in [28] describes the contents and processes involved in a learning unit from a pedagogical perspective through an information model with semantic aggregation. An EML has also the purpose of ensuring reusability and interoperability.

In February 2003, the North American consortium IMS undertook to study and provides a language of specification Learning Design called IMS-LD V1.0 [29].

IMS-LD V1.0 provides a modeling conceptual framework to implement Learning Units and claims to offer a good compromise between pedagogical approaches and specific learning units description.

Technically, through IMS-LD, a lesson plan extracted from a general or specific database [19] can be extracted, through the following generic parameters:

1. Roles' descriptions

2. Activities

3. Environment

4. Methods

5. Properties

6. Conditions

7. Notifications

IMS-LD allows the transformation of a lesson plan into learning units, formally described and executable with an engine-based IMS-LD editor (Copper core for example) [20]. These executable units can be designed from the outset using a publisher [21] or Reload [22]. They can be modified from existing examples stored in a directory (ex LN4LD (2004)) or Dspace. The Netherlands Open University (OUNL Open University of the Netherland) has set itself the task of provide engines, editing tools and full documentation of the IMS LD specification with sample applications. Since 2004, OUNL has participated in the dissemination effort led by the European project UNFOLD and involving many universities. 


\section{$3 \quad$ Perception Study}

\subsection{Generalities}

According to "one to one" interviews with 110 higher education professors participating on a pedagogical training in Hassan II University on 2019 (e-learning certification), questioned about learning attitude of higher education student:

1. Student can't take a lecture of 4 hours with attention,

2. He is doing less note taking,

3. He follows the practical work with more attention than the course

4. He does not understand oral explanations effectively

5. He works less at home

6. He does not learn by heart

7. He easily loses the lead between the parts of the course

8. He has trouble understanding for theoretical concepts

9. He does not read much

10. He works at the last minute and only prepares for the exam.

As for the educational environment, it has not changed much:

1. Barely equipped rooms with a video projector and a computer.

2. Students do not have access to digital devices;

3. Course materials are not updated in general (background and form);

4. Digitization and computerization projects initiated by universities in collaboration with the ministry have a management impact without any educational impact;

5. The exchange between the teacher and the student is informal.

6 . The documentary research of students is random on the internet.

To check these observations and to propose a new pedagogical model adequate to Moroccan university, we launch a perception study of Moroccan higher education student and its working environment.

\subsection{Study and analysis}

According to The engineering education state of art done in 2018 by MIT [30] , the most effective approach to measuring the impact of university programs on student learning, is the interview feedback of students (graduated or not). It's the reason why we choose to launch a perception study of Moroccan university learning approaches and environment from students' point of view. Readers interested on the study questions can find it here.

We questioned till now 1050 higher education students from Hassan II University. These students belong to different faculties and engineering schools of the university as shown in the graph bellow: 


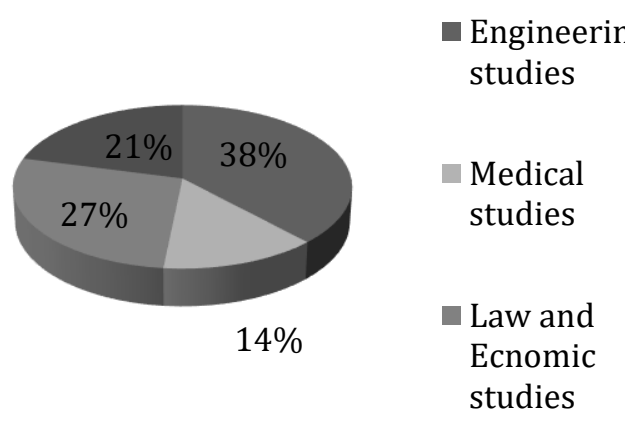

Fig. 2. Questioned population

The questions were mainly about three principal axes:

1. Actual pedagogical model evaluation.

2. Student satisfaction about their trainings.

3. The use of ICT in daily learning.

\subsection{Pedagogical model evaluation and students satisfaction}

All over the word, every higher education system has its own pedagogical view based on many curriculums. The best educational practices include user driven design, technological view for entrepreneurship and active project-based learning. The decision of practices to use should be taken through a field study with experts and student. It is the reason why our first axe was the pedagogical model evaluation by student as the most concerned stakeholders:

The perception study of Moroccan university we did, shows that $74 \%$ of the questioned students are not satisfied with the actual pedagogical system and only $26 \%$ are. More than $50 \%$ of them disagree with French as a learning language. 76,4\% of them said that the curriculum contains many important subject but it's not enough to master scientific techniques and be able to apply them.

Only $7,7 \%$ of them follow in class which means that the educational practices are not convenient or/and the way taught subjects are presented is not interesting for them.

Students were also asked about their level of mastery of the subjects taught and found that the majority (more than $30 \%$ ) feel rather well compared to the exam scores they obtain, to their ability to solve problems and to their ability to apply them in their professional experiences.

One thing more is that $67 \%$ are not satisfied with their level of mastery of the elements and modules of their initial training. They think that these modules and elements are outdated and they are unable to make connection between them during the years of previous training. 
Students claim the non-interactivity of courses and their theoretical aspect. They prefer examples and interactive discussions instead of classical structured courses. As for the evaluation mode, $57,7 \%$ of the students prefers making projects instead of answering courses questions.

The table below summarizes the Moroccan university satisfaction indicators according to the perception study:

Table 2. Satisfaction indicators

\begin{tabular}{|l|c|c|}
\hline \multicolumn{1}{|c|}{ Indicator } & Agree \% & Disagree \% \\
\hline Satisfaction with the actual pedagogical system & $26 \%$ & $74 \%$ \\
\hline Importance of the actual curriculums & $76,4 \%$ & $23,6 \%$ \\
\hline French as learning language & $50 \%$ & $50 \%$ \\
\hline Teachers explanations are important and followed & $7,7 \%$ & 92,3 \\
\hline Satisfaction with level of mastery of the taught subjects & 33 & $67 \%$ \\
\hline Making projects work as evaluation mode & $57,7 \%$ & 42,3 \\
\hline
\end{tabular}

The Ministry of Higher Education has 13 universities throughout the kingdom, with a total of 120 institutions (schools, institutes and faculties). As a result of the staffing programs, these institutions have one or more web pages, a digital working environment, Wi-Fi networks, multimedia rooms, and amphitheaters equipped with computers and video projectors. These universities also have ERP for teaching and student organization and management, and many of them have developed a distance learning area.

Meanwhile, according to the perception study, students complete their comprehension and master of taught subjects by: many resources as shown in the figure below:

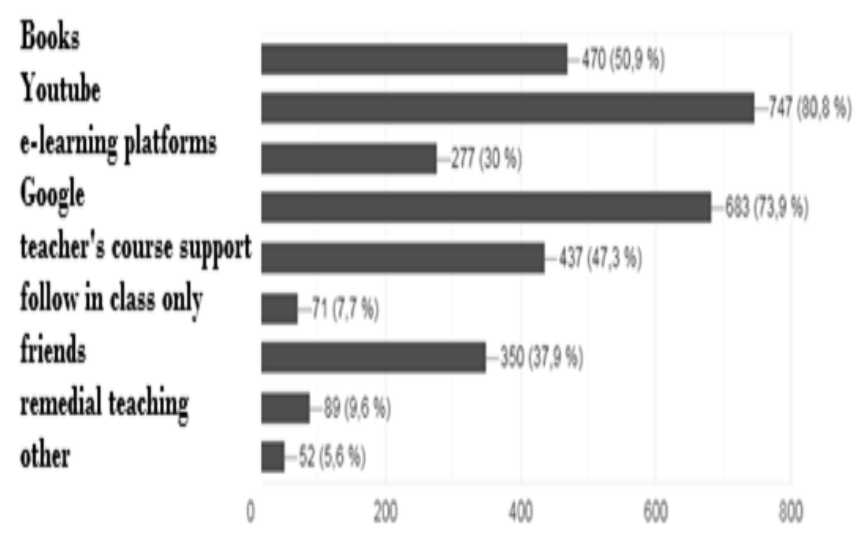

Fig. 3. Complementary learning tools and sources

YouTube and Google are the main information sources for Moroccan high education students, and only $42 \%$ of the 1050 Questioned students know what is e-learning, and only 35\% know about MOOCs; which means that these aspects do not actually appear in the current pedagogical model despite the use of ICT. 
As for students' expectations, $63 \%$ of them are interested in an e-learning platform from teachers all over the world and not only from their schools and universities. They are ready to login, and to identify their comprehension and learning abilities level. They prefer videos as course support to show technical details and skills and they consider it important to communicate with colleagues, teacher trainers and socioeconomic stakeholders such as companies and organizations trough the e-learning platform. Students need certifications as well to prove their mastery of taught modules.

So, if we come across variations of students learning attitude and those of the educational environment while taking into account the technological and scientific evolution that has invaded the way of life of people, we can deduce that it is absolutely necessary to set up a scenario driven model of Information and Communication Technologies based on pedagogical engineering to initiate the digital university in Morocco.

It's the aim of the next section, where we are going to propose an educational engineering model to deal with the current Moroccan university problems and satisfy student expectations.

\section{$4 \quad$ Proposed Educational Model}

These last ten years have been marked by two major trends in streamlining deployment ICTs in learning. The first advocate's educational engineering approach focused on process, while the second proposes a document list paradigm based on indexing and aggregating learning objects. These two approaches have recently interested in incorporating the proposed advances in the field of Learning Design.

According to literature, it is not the objects of knowledge that are the success keys of a learning environment, but the pedagogical scenario adopted by teachers. It is why we propose a scenario driven Meta model for Moroccan higher education based on the IMS DL specification:

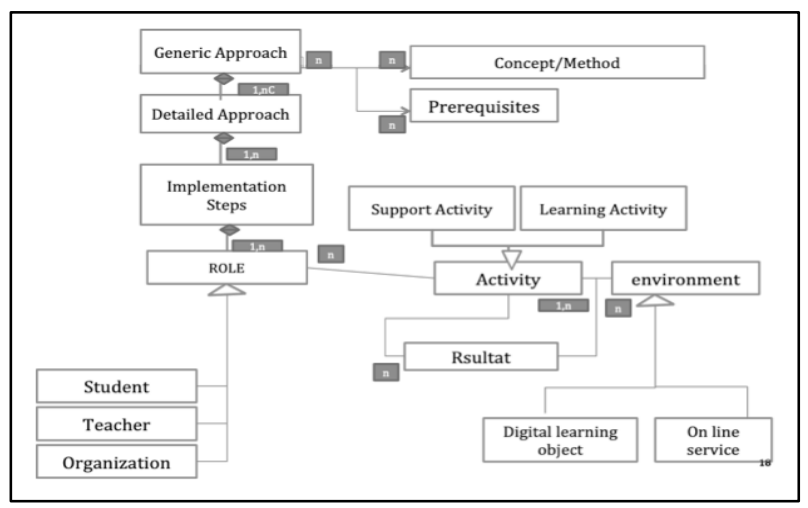

Fig. 4. IMS-LD proposed model 
Let's explain the model in a real classroom first: Every course is made from many concepts or method to be explained to a student as a target. Every taught concept or method has one or many prerequisites to take into consideration before explaining it. The teacher according to this model should absolutely fixes a generic approach to explain the concept; this generic approach should be one of the recognized pedagogical approaches such as constructivism [23], blended learning [24], collaborative learning [25] and active learning [26]. The teacher is not obliged to use only one approach for the entire course but he is allowed to combine two or more approaches depending on the situation, the public and the environment. Detailed approaches should be chosen, implemented and documented step by step in this case. One more thing in this level is that the mapping of the course into a reusable teaching object is essential work during the design level with an effective use of ICT through online services and digital learning objects.

Following the IMS DL method, we implement our model trough the manifest.xml file and deploy it first in "Moodle" as actual Hassan II University e-learning platform.

The proposed meta-model is based on IMS-LD specification which implements the theatre metaphor. In our case we focus on concept or method that a teacher presents to a student having prerequisites, this concept or method has many possible pedagogical generic approaches as said before. Teacher should detail this method according to this concept or method pedagogical characteristics and then implements this detailed approach in many basic steps. Every step is done either by the teacher himself or by the student or by the organization where the student expects to work or to practice this concept or method. Each Role has many activities, which are either learning activities or support activities in an environment made from digital learning objects and on line services. As for learning activities, they are principal activities that are obligatory for concept explanation steps implementation. We don't want to give examples in purpose because it depends on the taught subject and population.

Other important point is that the proposed model has transformation dimension, because it's actually impossible to launch a redesigning model for several strategic, financial and human reasons [27], which covers many points in the Moroccan university student learning approach. The model implementation should be done in the same time through e-learning platform and a well scripted course. This course orientation ensures the ruse of pedagogical objects and its incremental evolution.

The most important point is the necessity of ICT use for the new model since student use digital tools in their daily life, and this in many layers of the proposed model, the first one is the digital learning objects and the second one is online services. Other digital possibilities are also available in this model for learning and support activities.

One last thing, science and technology learning is experiencing an exponential evolution in knowledge, techniques and methodologies. It is no longer the time to teach the same course for about ten years in the same way. In addition, students are solicited in an evolving and continuously changing work market. They must be prepared during their pedagogical training to face business context successfully. 


\section{$5 \quad$ Results and Discussion}

This article is about a project of the educational engineering led by Moroccan researchers from the National School of Electricity and Mechanics and the Faculty of Legal and Economic Sciences of Hassan II Casablanca University. Our goal is to design and implement an agile and scalable educational model adaptable to the needs and expectations of today's student by implementing the digital and educational devices necessary to create a competent social actor.

The proposed meta-model offers a project-based curriculum structured around small and medium group learning with multidisciplinary focus. It combines oncampus project-based learning with online learning and off-campus work-based learning and allows bottom-up innovation and development of the regional entrepreneurial ecosystem, and this through the collaboration of the three roles (teacher, student and organization) with the variety of learning approaches and activities and the integration of digital solutions.

The meta-model was tested in his first version, for engineering school students: electrical, mechanical and computer sciences engineering total of $\mathbf{2 2 4}$ students, 5 learning groups and 3 learning subjects: “Relational Databases", "software quality assurance" and "data governance".

Trained students were satisfied and their results were significantly better than last year and the year before (the new model is tested in 2019; in 2018 and 2017 the classical model was adopted). Their implication in end of training project was $40 \%$ more than last year (using the classical model). They asked for more documents and links to learn more about subjects in addition to showing more interest to explanations.

\section{matisfied not satsfied}

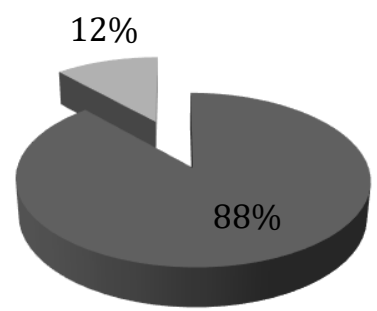

Fig. 5. Students satisfaction with the new model 


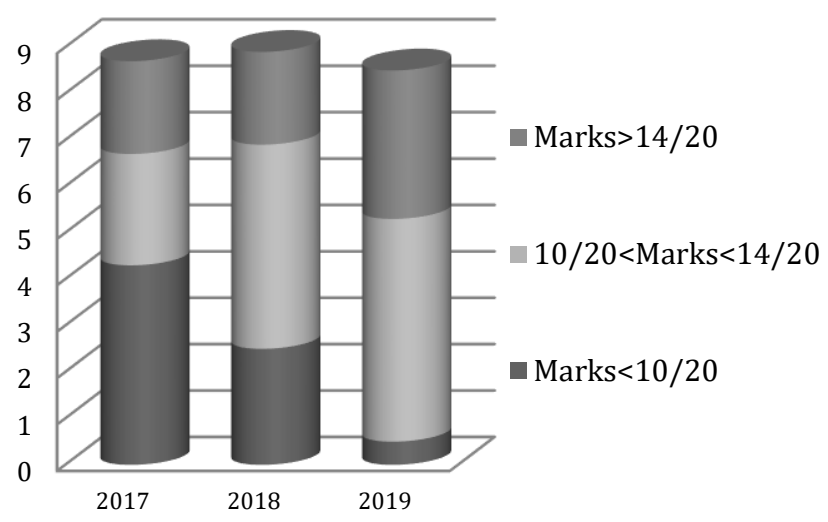

Fig. 6. Students Marks variations from 2017 to 2019

In fact, the objective is to have a student who masters technicality and correctly applies theoretical concepts and can effectively solve problems, who adapts to the constraints of the entrepreneurial environment and has a team spirit, who is initiated to research and innovation and open to new training. This profile is the core of Moroccan digital university pedagogical meta-model either for technician, engineer, or master students. Through a problem-based approach and a simulation of reality (project and company at the center of the training), the student can be trained while developing his technical, human and managerial skills. The student is therefore at the center of the pedagogical model as a dynamic actor.

\section{Conclusion and Perspectives}

In this article, we proposed, a pedagogical meta-model specific to the Moroccan university environment as far as ICT are concerned. We started this article with an introduction about the importance of ICT and their impact on higher education. We gave Educational learning models stat of art in addition to an overview of Pedagogical engineering and IMS as a language design. After a comparison study of existing EML, we focused the new model on TPACK and we use the IMS LD to implement it.

The new model calls upon three stakeholders, namely the student, the teacher and the company. It makes it possible to deploy several teaching methods and objects to explain a concept or a technique in the form of a structured scene.

We carried out a first evaluation of the model by its implication on different training groups, and it makes good results compared to the classical model.

As perspectives, we will make piloting Scenarios to validate the model. We are also working on a smart Moroccan university learning platform that implements specifically this pedagogical engineering model. 


\section{$7 \quad$ References}

[1] Wang, Q. (2008). A generic model for guiding the integration of ICT into teaching and learning. Innovations in education and teaching international, 45(4), 411-419. https://doi.org/10.1080/14703290802377307

[2] Gretter, S., \&Yadav, A. (2016). Computational thinking and media \& information literacy: An integrated approach to teaching twenty-first century skills. TechTrends, 60(5), 510516. https://doi.org/10.1007/s11528-016-0098-4

[3] Hamilton, E. R., Rosenberg, J. M., \&Akcaoglu, M. (2016). The substitution augmentation modification redefinition (SAMR) model: A critical review and suggestions for its use. TechTrends, 60(5), 433-441. https://doi.org/10.1007/s11528-016-0091-y

[4] Torres, E. (2018, March). Promoting Workforce Education in University Programs with TPACK and Experiential Learning. In Society for Information Technology \& Teacher Education International Conference (pp. 1105-1108). Association for the Advancement of Computing in Education (AACE).

[5] Spector, J. M., Merrill, M. D., Elen, J., \& Bishop, M. J. (Eds.). (2014). Handbook of research on educational communications and technology (pp. 413-424). New York, NY: Springer

[6] Hall, G. E., \&Hord, S. M. (2011). Implementing change: Patterns, principles, and potholes (3rd ed.). Boston: Pearson.

[7] Stockless, A., Villeneuve, S., \&Gingras, B. (2018). Maitrise d'outils technologiques: son influence sur la compétence TIC des enseignants et les usages pédagogiques| Mastery of Digital Tools: The Influence on Information and Communication Technologies Competency and Pedagogical Use. Canadian Journal of Learning and Technology/La revue canadienne de l'apprentissage et de la technologie, 44(2). https://doi.org/10.21432/cjlt27581

[8] Morais, A., Neves, I. (2001). Pedagogic social contexts: studies for a sociology of learning. In: Morais, A., Neves, I., Davies, B., Daniels, H. (Eds.), Towards a sociology of pedagogy: the contribution of Basil Bernstein to research (pp. 185-221). New York: Peter Lang.

[9] Justice, B. (2017). Curriculum Theory and the Welfare State. Espacio, Tiempo y Educación, 4(2), 19-41

[10] Stockless, A. (2018). Fenwick, T., \& Edwards, R. (2016). Exploring the impact of digital technologies on professional responsibilities and education. European Educational Research Journal, 15(1), 117-131, https://doi.org/10.1177/1474904115608387

[11] Breiner, J. M., Harkness, S. S., Johnson, C. C., \& Koehler, C. M. (2012) What Is STEM? A Discussion About Conceptions of STEM in Education and Partnerships. School Science and Mathematics, 112(1), 3-11. https://doi.org/10.1111/j.1949-8594.2011.00109.x

[12] Edwards, A. K. (2015). Developing Teachers using Human Performance Technology: Considering the Nexus between Purpose-Driven Life and Curriculum Leadership. JOURNAL OF EDUCATIONAL POLICY AND ENTREPRENEURIAL RESEARCH, 2(5), 165-174.

[13] Lortet, A. (2018). Devis ludique pour les modèlesd'ingénierie de dispositifs pédagogiques Gamification Specifications for Engineering Models of Educational Devices. Canadian Journal of Learning and Technology/La revue canadienne de l'apprentissage et de la technologie, 44(3). https://doi.org/10.21432/cjlt27637

[14] Maina, M. F. (2010). Design of pedagogical scenarios: Adapting the MISA method to the IMS LD specification (Doctoral dissertation, Universitat Oberta de Catalunya). 
[15] Vengrin, C., Westfall-Rudd, D., Archibald, T., Rudd, R., \& Singh, K. (2018). Factors affecting evaluation culture within a non-formal educational organization. Evaluation and program planning, 69, 75-81. https://doi.org/10.1016/j.evalprogplan.2018.04.012

[16] Akilli, G. K. (2007). Games and simulations: A new approach in education. In Games and simulations in online learning: Research and development frameworks (pp. 1-20). IGI Global. https://doi.org/10.4018/978-1-59904-304-3.ch001

[17] Stolovitch, H. D., \& Keeps, E. J. (2003). Engineering effective learning toolkit. Pfeiffer.

[18] Mason, R., \&Rehak, D. R. (2003). Keeping the learning in learning objects: Learning objects: what is the problem? In Reusing Online Resources (pp. 38-52). Routledge.

[19] Shea, P., McCall, S., \&Ozdogru, A. (2006). Adoption of the multimedia educational resource for learning and online teaching (MERLOT) among higher education faculty: Evidencefrom the State University of New York Learning Network. MERLOT Journal of Online Learning and Teaching, 2(3). https://doi.org/10.28945/2587

[20] Martens, H., \&Vogten, H. (2005). A reference implementation of a Learning Design Engine. In Learning Design (pp. 91-108). Springer, Berlin, Heidelberg. https://doi.org/10.1 007/3-540-27360-3_6

[21] Van Der Vegt, G. S., \&Bunderson, J. S. (2005). Learning and performance in multidisciplinary teams: The importance of collective team identification. Academy of management Journal, 48(3), 532-547. https://doi.org/10.5465/amj.2005.17407918

[22] Kuiper, E., \&Volman, M. (2008). The web as a source of information for pre-service teachers in K-12 education. In J. Coiro, M.Knobel, C. Lankshear\& D. Leu (Eds.), Handbook of research on new literacies (pp. 241-266). New York: Lawrence Erlbaum Associates

[23] Ocak, M. (2010). Blend or not to blend: a study investigating faculty members perceptions of blended teaching. World Journal on Educational Technology, 2(3), 196-205

[24] Santangelo, T. (2009). Collaborative problem solving effectively implemented but not sustained: A case for aligning the suny the moony and thestar. Exceptional Children, 75(2), 185-209. https://doi.org/10.1177/001440290907500204

[25] Shekhar, P., Prince, M., Finelli, C., Demonbrun, M., \& Waters, C. (2019). Integrating quantitative and qualitative research methods to examine student resistance to active learning. European Journal of Engineering Education, 44(1-2), 6-18. https://doi.org/10.1080/ $\underline{03043797.2018 .1438988}$

[26] Vermeren, P. (2011). La formation des élites marocaines, miroir de la mondialisation? Le Télémaque, (1), 53-66. https://doi.org/10.3917/tele.039.0053

[27] Mukherjee, D. (2014). Factors of management education in India as perceived by learners and providers: An empirical study. Vision, 18(2), 73-80. https://doi.org/10.1177/ $\underline{0972262914527872}$

[28] Alharbi, A., Henskens, F., \& Hannaford, M. (2014). personalised learning object system based on self-regulated learning theories. International Journal of Engineering Pedagogy (iJEP), 4(3), 24-35. https://doi.org/10.3991/ijep.v4i3.3348

[29] Tibola, L. R., Pereira, C. E., \& Tarouco, L. M. R. (2014). Improving performance to engineering students through virtual labs and its monitoring in cockpit. International Journal of Engineering Pedagogy (iJEP), 4(4), 43-50. https://doi.org/10.3991/ijep.v4i4.3957

[30] Graham, R. (2018). The global state of the art in engineering education. Massachusetts Institute of Technology (MIT) Report, Massachusetts, USA. 


\section{Authors}

Meriyem Chergui is a professor in the Higher National School of Electricity and Mechanic, in Mathematics and Computer sciences department. She had engineering degree on Computer sciences in 2010 from Hassania Engineering School, Casablanca, Morocco. She had PhD from the Higher National School of Electricity and Mechanic in engineering sciences Casablanca Morocco. Email:chergui.meriyem@ gmail.com

Ahlam Tahiri is a PhD student in the Higher National School of Electricity and Mechanic, she is a computer science engineer from Polytech Lile. She is also an IT coach and manager.

Aziza Chakir is a professor in the Faculty of economic and social legal sciences, Casablanca, Morocco. She had engineering degree on BI in 2009 from ENSIAS Engineering School, Rabat, Morocco. She had PhD from the Higher National School of Electricity and Mechanic in engineering sciences, Casablanca, Morocco.

Hajar Mansouri is a professor in the Higher National School of Electricity and Mechanic, in Elecricity department. She had PhD from the Higher National School of Electricity and Mechanic in engineering sciences Casablanca Morocco.

Article submitted 2019-11-18. Resubmitted 2020-01-07. Final acceptance 2020-01-07. Final version published as submitted by the authors. 